\title{
ESTUDO COMPARATIVO DE FERRAMENTAS COMPUTACIONAIS PARA MODELAGEM GEOMÉTRICA E CUBAGEM DE MACIÇOS ROCHOSOS
}

\author{
S. S. ROCHA ${ }^{1}$, J. C. SOUZA ${ }^{2}$, I. M. CARMO ${ }^{3}$, H. C. RODRIGUES ${ }^{4}$ \\ 1,2,3,4 Universidade Federal de Pernambuco \\ eng.suelen.rocha@hotmail.com*
}

Submetido 18/11/2016 - Aceito 12/02/2018

DOI: $10.15628 /$ holos.2018.5361

\section{RESUMO}

O desenvolvimento mineiro ocorre em diversas etapas. $\mathrm{Na}$ fase inicial da atividade de mineração realiza-se uma análise prévia para quantificação e qualificação do minério passível de ser extraído de modo rentável, constituindo-se em uma gestão dos recursos e reservas minerais. Essa etapa é fundamental por caracterizar-se como fator de determinação para maximização da recuperação do minério, o que implica na vida útil e lucratividade do empreendimento mineiro através do reconhecimento geológico do depósito mineral que está sujeito de ser materializado por vários tipos de modelos. Neste contexto, é fundamental a elaboração de um modelo geomorfológico representativo do corpo mineralizado baseado em informações recolhidas por meio de técnicas de prospecção geológica e levantamentos de campo. Por ser realizado na fase
\end{abstract}

inicial, a precisão dos resultados desses trabalhos geralmente não se constitui fator decisivo na seleção dos alvos de pesquisa de detalhe devido à carência de dados de campo e necessidade de custos reduzidos, sendo admitidas variações de até $30 \%$ nos valores determinados. 0 desenvolvimento contínuo das ferramentas computacionais permite que modelos geomorfológicos das ocorrências minerais possam ser elaborados de maneira rápida e precisa com baixo custo operacional. Neste sentido, o objetivo deste trabalho foi desenvolver uma metodologia para modelagem geométrica de maciços rochosos a partir do uso de softwares de baixo custo e ilustrar na prática a aplicação da mesma para determinação do volume de maciços rochosos.

PALAVRAS-CHAVE: Modelagem, Maciço rochoso, Ferramentas computacionais, Avaliação de reservas.

\section{COMPARATIVE STUDY OF COMPUTATIONAL TOOLS FOR GEOMETRIC MODELING AND EVALUATION OF ROCK MASSES RESERVES}

\begin{abstract}
The mining development occurs in several stages. In the initial phase of mining activity carried out a preliminary analysis to quantify and qualify the ore that can be mined profitably, being in the management of mineral resources and reserves. This step is critical because it is characterized as determining factor to maximize ore recovery, which involves the life and profitability of the mining project through the geological reconnaissance of mineral deposit that is subject to be materialized by various types of models. In this context, it is essential to create a representative geomorphological model of the mineralized body based on information collected through techniques of geological prospecting and field surveys. To be performed in the initial phase, the accuracy of the results of such work generally does not constitute a decisive factor in the selection of targets for detail research due to the lack of field data and the need for reduced costs, variations being permitted up to $30 \%$ on certain values. The continuous development of computational tools allows geomorphological models of mineral deposits can be developed quickly and accurately with low operating cost way. In this sense, the objective of this study was to develop a methodology for geometric modeling of rock masses from the use of low cost software and illustrate the practical application of it to determine the volume of rock masses.
\end{abstract}

KEYWORDS: Modeling, Rock mass, Computational tools, Evaluation of reserves. 


\section{INTRODUÇÃO}

Na mineração, a gestão de recursos e reservas minerais é fundamental para a quantificação e qualificação das reservas. Esta gestão se baseia principalmente no reconhecimento geológico do depósito mineral que está sujeito de ser materializado por vários tipos de modelos. Assim, o problema inicial detém-se no desenvolvimento de um modelo apropriado ao corpo mineralizado, o qual é baseado em informações recolhidas por meio de técnicas de prospecção geológica e levantamentos de campo. Todavia, além da precisão na quantificação dos recursos e reservas, o interesse pela maximização da recuperação do minério é fundamental, visto que tal maximização afetará a vida útil, a lucratividade e sustentabilidade do empreendimento.

Um dos aspectos fundamentais para a avaliação do potencial técnico-econômico de um depósito mineral é a construção de um modelo tridimensional. A sequência de avaliação tem algumas premissas fundamentais, tais como: enquadramento geográfico e geológico, geometria tridimensional do depósito mineral, teor médio do depósito, distribuição espacial dos teores, aspectos políticos, ambientais, técnicos etc.

Durante muito tempo, as denominadas técnicas clássicas tais como os métodos dos polígonos e do inverso das distâncias foram as mais utilizadas como metodologias de cubagem de jazidas, as quais permitem realizar o cálculo de reservas usando técnicas de interpolação através de fatores médios ponderados (teores, espessuras e volumes), os quais são então aplicados a áreas ou volumes de influência. Entretanto, a praticidade e confiabilidade dos processos que os computadores trouxeram à mineração através dos softwares, associados à sua capacidade de representar as distribuições dos teores ocorrentes num depósito mineral de um modo mais preciso fizeram com que o seu uso se tornasse cada vez mais fundamental nos empreendimentos mineiros.

Ainda assim, nas minerações de materiais com baixo valor econômico agregado como a produção de agregados para construção civil, existe uma grande dificuldade relacionada ao alto custo de utilização das ferramentas computacionais para avaliação de reservas e definição dos limites da lavra. Assim, considerando que na fase preliminar de avaliação de ocorrências de maciços para produção de brita os dados geológicos e geomorfológicos são escassos, os recursos alocados são de baixo vulto e a precisão dos resultados não é crítica pelo fato de o teor do minério não configurar-se fator decisivo para a viabilidade do empreendimento mineiro, é possível a geração de modelos geométricos da morfologia dos maciços em estudo preliminar a partir de softwares de fácil acesso e baixo custo como o Google Earth e ortofotocartas georreferenciadas.

Neste contexto, o principal objetivo deste trabalho foi desenvolver uma metodologia computacional para a modelagem geométrica de maciços rochosos utilizando ferramentas computacionais de baixo custo visando a determinação do volume de maciços rochosos em uma fase preliminar de avaliação, indicando alternativas de fácil acesso e baixo custo para avaliação preliminar de jazidas minerais para produção de agregados. 


\section{REVISÃO DA LITERATURA}

Define-se recurso mineral como a ocorrência mineral identificada, in situ, com potencial de ceder minerais de interesse econômico, avaliado com base nas informações de amostragem disponíveis, mas que não foi submetida a uma avaliação econômica, visando inicialmente à construção do modelo do depósito mineral; são classificados em recursos medidos, indicados e inferidos levando em consideração principalmente a continuidades das mineralizações. Já uma reserva mineral corresponde à parte do recurso (medido e/ou indicado) com potencial para lavra que pode ser produzido economicamente, em razão de custos, demandas e preços atuais, e subdivide-se em provada e provável. Frequentemente, em virtude de fatores como avanços tecnológicos e flutuações de preços das commodities minerais, durante a explotação torna-se possível aproveitar materiais que não estavam classificados como reservas (Curi, 2014).

A avaliação de recursos minerais consiste em uma tentativa sistemática de qualificação e quantificação de reservas minerais de interesse econômico, tendo por objetivo a obtenção da melhor estimativa da tonelagem e da qualidade de um corpo de minério e a determinação do erro associado a tais estimativas em um determinado intervalo de confiança. A precisão das estimativas na avaliação das reservas minerais é dependente da quantidade, qualidade e distribuição espacial das amostras e do grau de continuidade da mineralização, que corresponde basicamente à regularidade do corpo de minério (Curi, 2014).

Essa avaliação pode compreender uma sequência de atividades com uma avaliação mineral regional utilizando-se de amplos recursos e uma análise mais detalhada com uma reavaliação de uma ou mais sub-regiões de maior potencial econômico ou também compreender uma avaliação de recursos com em um determinado estágio a partir da acumulação de dados. Antes mesmo da avaliação de recursos detalhada, através de mapas geológicos aliados a dados geoquímicos, geofísicos e de perfuração e estudos de viabilidade detalhados de depósitos específicos, é possível obter uma aproximação da região a ser estudada através de técnicas de avaliação, quais sejam interpolação, extrapolação ou analogia (Carmo, 2013; Revuelta \& Jimeno, 2012).

Os custos com atividades de avaliação de recursos minerais variam amplamente desde milhares a milhões de reais (Hustrulid, Kuchta \& Martin, 2013). Na prática mineira existem vários procedimentos empregados para execução dessa avaliação, os quais têm sido constantemente melhorados para produzirem resultados mais precisos e confiáveis. Segundo Yamamoto (2001) e Sad e Valente (2007), os métodos para avaliação de reservas podem ser classificados em três grandes grupos: métodos clássicos, métodos estatísticos e métodos geoestatísticos.

Os métodos clássicos ou convencionais consistem em avaliações baseadas em metodologias científicas considerando aspectos quantitativos que permitem realizar o cálculo de reservas usando fatores médios ponderados (teores, espessuras e/ou volumes) os quais são então aplicados a áreas ou volumes de influência (Carmo, 2013; Curi, 2014). Tais métodos fundamentam-se em dois princípios: princípio das iguais áreas de influência, que postula a extensão do valor verificado em um ponto para uma dada distância e, posteriormente, para uma dada área e/ou volume de influência; e princípio das variações graduais, o qual diligencia a variação contínua ou gradual do valor verificado entre pontos amostrais. Como exemplos de 
métodos do princípio das áreas de influência tem-se o método das figuras geométricas, que se subdivide em método dos polígonos (no plano) ou prismas (no espaço) e consiste em extrapolar os valores obtidos em uma determinada amostra a uma determinada área ou volume de influência, e para tal extrapolação são traçadas as áreas de influência de cada furo que são determinadas pelas mediatrizes correspondentes a furos contíguos. O método é falho, pois não contorna o erro de extensão, que é cometido quando se extrapola o valor verificado para um determinado intervalo de sondagem para a totalidade do seu volume de influência (Revuelta \& Jimeno, 2012; Curi, 2014).

Já como exemplos de métodos do segundo princípio têm-se os métodos das curvas de isovalores, que se subdivide em método de análise das superfícies de tendência e o método do inverso da distância. O método de análise das superfícies de tendência ou método dos contornos baseia-se no traçado de curvas representativas dos lugares geométricos de igual valor, que são construídas por interpolação ou extrapolação dos valores determinados em amostras adjacentes (Revuelta e Jimeno, 2012; Curi, 2014). O método do inverso da distância fundamenta-se no fato de que teores de amostras de furos vizinhos, em relação a um determinado ponto ou bloco do depósito, são proporcionais ao inverso das respectivas distâncias ou a uma potência destas. 0 princípio de avaliação é semelhante aos outros métodos, isto é, são estabelecidos blocos de avaliação aos quais se atribuem espessuras e teores e as reservas são obtidas a partir do seu volume. De modo geral, o método do inverso de uma potência da distância recorre a uma interpolação local, ou seja, só participam no cálculo os pontos amostrados mais próximos de cada ponto a quantificar (Gama, 1986a) onde aplica-se um fator de ponderação a cada amostra que rodeia o ponto central de um bloco mineralizado, que é o inverso da distância entre cada amostra e o centro do bloco, elevado a uma potência $n(3>n>1)$ e, segundo Barnes (1980), o valor de 2 ( $n=$ 2) é aquele que geralmente conduz a melhores resultados; desta forma, apenas as amostras que estão dentro de uma determinada zona de busca são ponderadas (Revuelta \& Jimeno, 2012; Curi, 2014).

Os métodos clássicos não quantificam os erros que são cometidos, tanto de estimação quando de extensão, na determinação de valores de reservas minerais, e também não avaliam se a quantidade de informação obtida é suficiente para o conhecimento da jazida. Ainda assim, estes métodos podem ser empregados para avaliar a adequadamente as reservas minerais mais simples e homogêneas, além de que suas técnicas de interpolação auxiliam bastante a determinação das reservas através das técnicas computacionais.

A utilização de métodos estatísticos e de modelos probabilísticos na avaliação de reservas minerais é prática comum, pois estes métodos interpretam a natureza aleatória das mineralizações considerando os princípios elementares da estatística convencional (Devore, 2006). A avaliação de reservas por estes métodos requer uma análise estatística dos dados oriundos das sondagens e das composições dos furos das sondagens, que tem por objetivo caracterizar e descrever numericamente através dos parâmetros estatísticos descritivos (média, variância, desvio-padrão, covariância e coeficiente de variação) as distribuições dos dados para melhor entendimento do comportamento das variáveis de interesse (teores médios e distribuição de frequência dos teores), que permitem ter-se uma ideia inicial da viabilidade técnico-econômica do depósito mineral e avaliar o percentual dos teores (Girodo, 2006). 
Os métodos de avaliação de reservas que mais progrediram foram os métodos geoestatísticos. Esses métodos: levam em conta a estruturação do depósito, pois os modelos geoestatísticos ajustam-se à realidade da variação dos teores no jazimento mineral; não promovem sub ou superestimação das reservas, pois seus estimadores são formulados para evitar erros sistemáticos; e fazem melhor uso das informações coletadas, pois os estimadores como a krigagem, por exemplo, avaliam todo o domínio proposto com variância mínima. Isso é possível pelo fato de a geoestatística considerar a distribuição espacial das amostras e tratar as variáveis como regionalizadas, possibilitando avaliar erros de estimação e introduzir distâncias de influência entre as amostras (Curi, 2014).

As variáveis usadas como base para cálculo dos valores (teores, espessuras etc.) são consideradas como uma realização de uma função aleatória $n$ dimensional dotada de certa função de autocorrelação, denominada variograma, que representa um sistema de interdependência estatística entre amostras vizinhas, sendo a primeira tarefa da avaliação geoestatística a definição dos variogramas globais da reserva mineral válidos para o campo homogêneo que se pretende avaliar. A função variograma mede a variância de valores entre pontos separados por uma distância definida: o aumento gradual da distância entre os pontos tende a aumentar a variância dos valores dos mesmos (Curi, 2014; Revuelta \& Jimeno, 2012).

Baseado nos modelos que interpretam os variogramas e seu ajuste, é necessário construir os estimadores dos valores médios das variáveis em análise e calcular o respectivo erro. Para tal utiliza-se a técnica denominada krigagem, em que o estimador empregado baseia-se em uma combinação linear de toda a informação disponível. Assim, a krigagem é um processo geoestatístico de estimação de valores de parâmetros no espaço quando considerados interdependentes pela análise variográfica, e refere-se ao modo de ponderar as diversas amostras disponíveis atribuindo pesos maiores a amostras mais próximas e pesos menores a amostras mais distantes fundamentada na ideia de que quanto maior a covariância entre uma amostra e o local que está sendo estimado, mais essa amostra deve contribuir para a estimativa (Yamamoto \& Landim, 2013).

Os métodos de avaliação de reservas descritos são utilizados e aplicados através dos métodos computacionais, inclusive os métodos clássicos. Esses métodos são os mais utilizados na área mineral, especialmente quando se trata de depósitos minerais de alto valor econômico e comportamento muitas vezes errático, devido à praticidade e confiabilidade dos processos que os computadores trouxeram à mineração através dos softwares, associados à sua capacidade de representar as distribuições dos teores ocorrentes num depósito mineral de um modo mais preciso. Essas características fizeram com que o seu uso se tornasse cada vez mais fundamental nos empreendimentos mineiros (Revuelta \& Jimeno, 2012).

Os métodos computacionais possibilitam a estimativa das reservas minerais e das reservas lavráveis, permitindo a definição dos limites da lavra (ou limite final da cava) através da modelagem tridimensional geométrica das jazidas e/ou depósitos, que consiste em uma representação matemática altamente precisa de dados ou pontos dispostos em três dimensões em um processo chamado triangulação (Curi, 2014). 
As técnicas computacionais possuem uma base teórica destinada a conferir maior confiabilidade às interpolações, através da definição do melhor estimador linear não-enviesado, que atribui teores aos blocos não amostrados de uma jazida mineral. Através da krigagem, o estimador pode calcular valores que, em média, são iguais ao valor real da jazida, baseando-se na hipótese de que o teor é uma variável regionalizada. Este método permite estimar não só os valores mais prováveis dos blocos intermediários de minério, mas também, os erros cometidos em tais avaliações (variância da distribuição), podendo desse modo assinalar os locais onde mais dados devem ser colhidos para se obter maior confiabilidade (Yamamoto e Conde, 1996).

A metodologia da modelagem geológica e geotécnica está dividida em modelagem geométrica e modelagem numérica. Recomenda-se um processo ou conjunto de critérios que avaliem toda a informação em unidades geológico-geotécnicas homogêneas. A superfície envolvente de um corpo mineral pode ser modelada como uma malha triangulada de pontos similar àquela utilizada para modelar superfícies por meio de modelos tipo Digital Terrain Model (Modelo Digital de Terreno - DTM), e o termo técnico em inglês para definir este tipo de modelo é wireframe (Figura 1) (Curi, 2014).

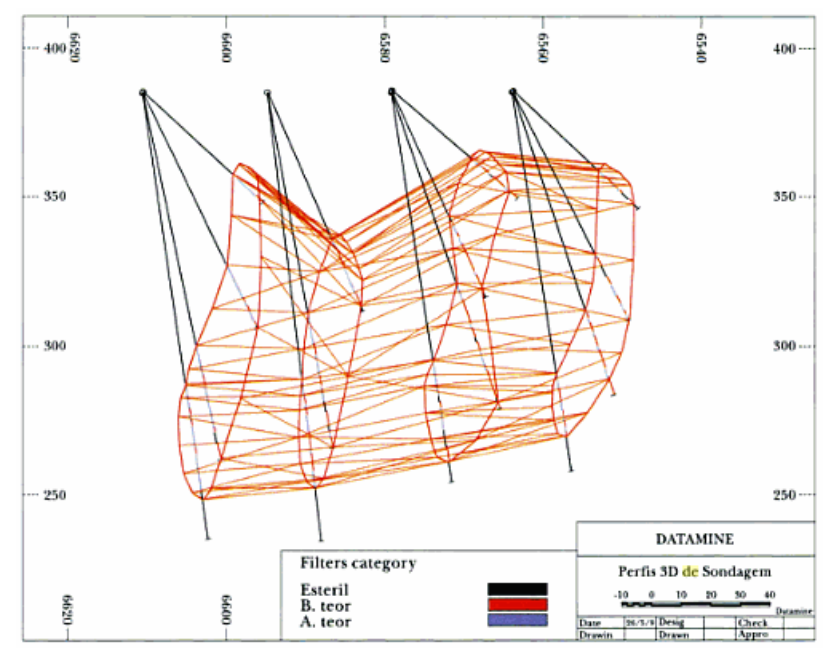

Figura 1: Modelo sólido triangulado tipo wireframe.

Fonte: Carmo (2013)

A construção de um wireframe pode ser exemplificada a partir da análise dos dados apresentados na figura acima. As quatro poligonais fechadas, representando seções transversais do corpo mineral, podem ser ligadas através de um algoritmo de triangulação automática de poligonais. Existem diversos tipos de algoritmos para esse fim no software DATAMINE STUDIO, e seu objetivo é produzir uma forma cilíndrica irregular cuja superfície é constituída por uma malha de triângulos. As extremidades do "cilindro" são fechadas também por uma malha triangulada.

Uma vez criado este modelo, o volume definido pelo seu contorno pode ser calculado de modo preciso e eficiente. Os modelos tipo wireframe representam apenas a superfície dos corpos minerais e não a variação de teores ou qualquer atributo espacial por meio da jazida; para representar essas variações utilizam-se os modelos de blocos (Tomi, 2001).

O modelo tridimensional de blocos ou modelo tecnológico de blocos (Figura 2) consiste em um conjunto de blocos de cubagem que compõem o depósito mineral que têm a forma geral de 
paralelepípedos com dimensões e formas similares e compatíveis com a densidade média de amostragem nas três direções. O volume de cada bloco representa a menor porção, unidade ou célula do corpo mineral a ser avaliada pelo modelo matemático, e a cada uma dessas unidades são atribuídas as informações relativas a geologia, geotecnia, valor dos produtos e custos para interpretação. A discretização de todo o domínio da jazida em blocos facilita a avaliação pelos métodos computacionais, e a atribuição dos valores a cada bloco é realizada pelas técnicas de interpolação tais como métodos das áreas de influência, do inverso da distância ou krigagem (Yamamoto, 2001; Curi, 2014; Hustrulid, Kuchta, \& Martin, 2013).

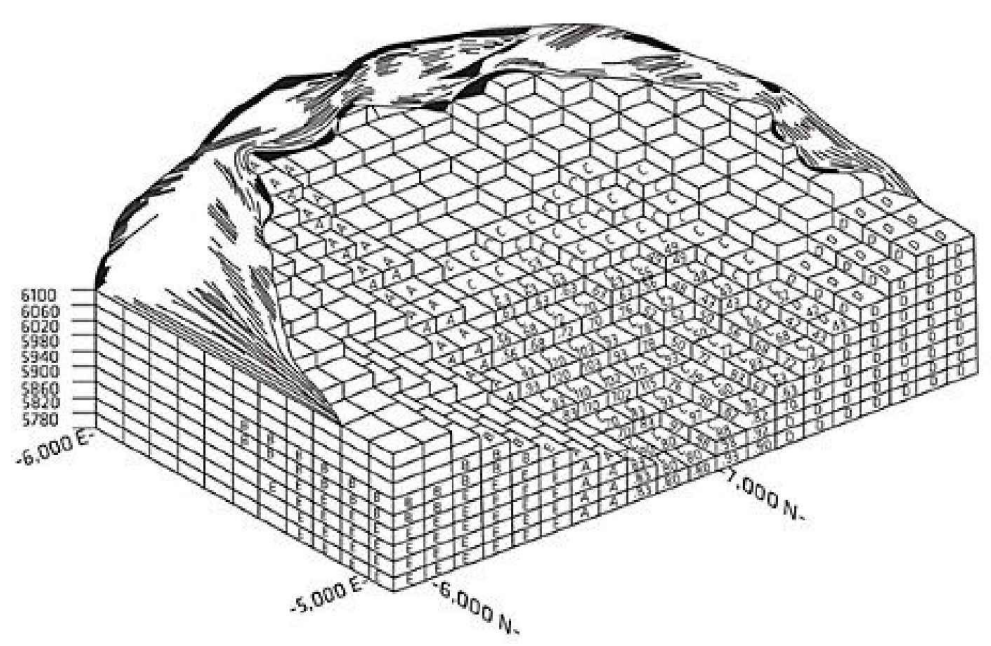

Figura 2: Modelo tridimensional de blocos de um depósito hipotético.

Fonte: Curi (2014)

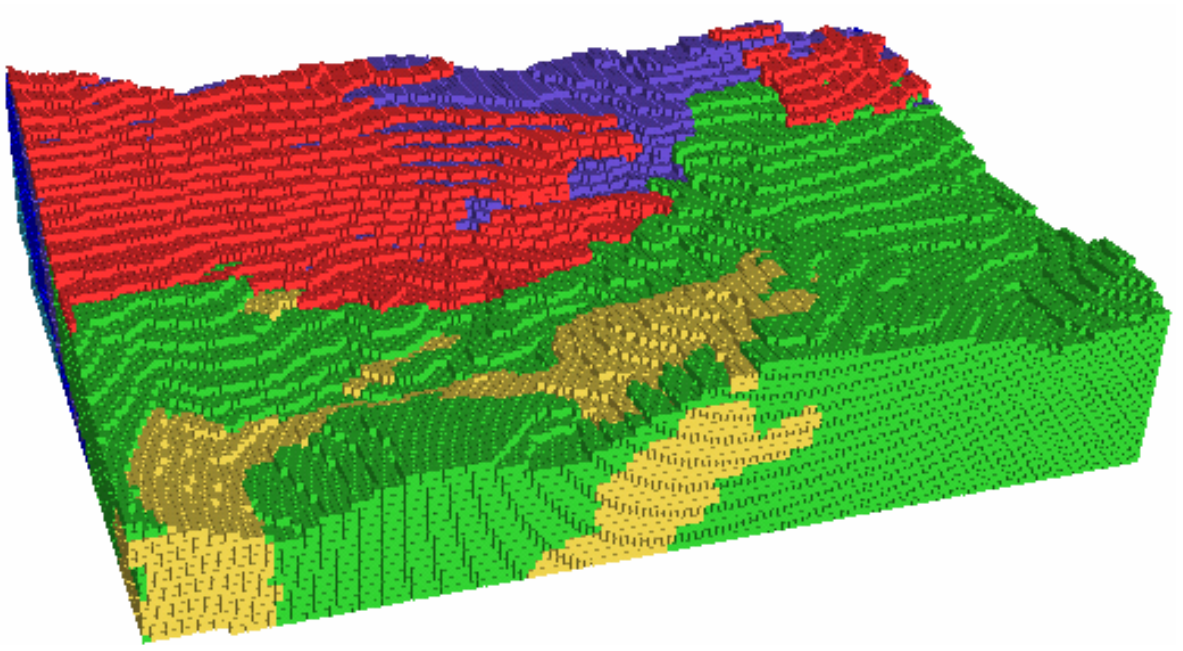

Figura 3: Modelo de blocos de um depósito hipotético com representação da topografia e geologia.

Fonte: Pinto \& Dutra (2008)

A criação do modelo de blocos requer basicamente quatro tipos de arquivos de dados: arquivo de furos de sondagem, arquivo de composição, arquivo de modelo de blocos vazio (não discretizado) e arquivo de superfície topográfica. O valor econômico dos blocos é determinado pela diferença entre as receitas obtidas com a venda do minério e os custos associados à sua extração (Curi, Neme, Silva \& Carneiro, 2011; Curi, Pereira, Sousa, \& Silva, 2013). 
O conhecimento dos recursos disponíveis e das reservas que estão associadas a diferentes geometrias de escavação a céu aberto e o estabelecimento dos limites finais dessas mesmas escavações pressupõe a elaboração prévia de um inventário mineral o qual é composto por um conjunto de blocos tridimensionais, cada um deles caracterizado por um determinado volume, por um teor em substância útil e por um certo valor econômico (Gama, 1974). Os limites finais de uma exploração mineira a céu aberto definem o tamanho e a forma da mesma no final da sua vida útil, garantindo a maximização da riqueza futura. Estes contornos finais definem a extensão da reserva economicamente explorável e a quantidade de material estéril a ser removido. Normalmente, marcam a fronteira limite além da qual a exploração não será considerada economicamente rentável (Carmo, Curi, \& Sousa, 2006).

O avanço da informática levou à generalização do seu uso em questões fundamentais como as que aqui se abordam. Segundo Wright (2000) apud Curi (2014), foi assim que se desenvolveram vários algoritmos para determinar o pit óptimo, tais como: Simulação (Axelson 1964, Pana - 1965, Fairfield e Leigh - 1969, Lee e Kim - 1979), Programação Linear (Meyer 1966), Programação dinâmica (Lerchs e Grossman - 1965, Johnson e Sharp - 1971, Koenigsberg 1982, Wilke e Wright - 1984, Shenggui e Starfield - 1985 e Wright - 1987), Teoria dos Grafos (Lerchs \& Grossman, 1965); Parametrização (François-Bongarçon e Marechal - 1976). Dentre esses, os que se destacam são a técnica dos cones móveis, o algoritmo de Lerchs e Grossman e o método da Parametrização (Carmo, Curi, \& Sousa, 2006).

Os diferentes algoritmos existentes para definição da reserva mineral lavrável e otimização dos limites finais da lavra agrupam-se em duas categorias:

- Heurísticos: ainda que não possam ser demonstrados matematicamente, a experiência mostra que funcionam satisfatoriamente. É o caso do método dos cones flutuantes (ou móveis);

- Rigorosos: aqueles cuja otimização tem uma completa demonstração matemática, como é o caso do método de Lerchs \& Grossman (otimização combinatória).

\subsection{Caracterização da área de estudo}

A área estudada está localizada no distrito de Jussaral, no sudoeste do município de Cabo de Santo Agostinho, que situa-se na porção sul da Região Metropolitana de Recife (RMR), estado de Pernambuco, e dista $41 \mathrm{Km}$ da capital. Inclui-se, em parte, na microrregião do Complexo Suape, no Estado de Pernambuco, Nordeste do Brasil e abrange uma área de $448,4 \mathrm{~km}^{2}$ correspondente a $16,28 \%$ da RMR e 0,45\% do território estadual (Figura 4). 


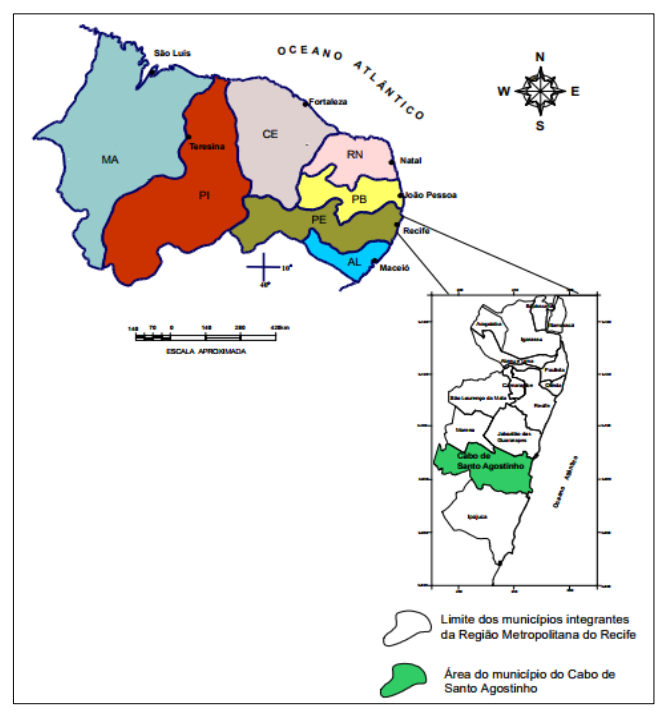

Figura 4: Mapa de localização da área.

Fonte: CPRM (2001)

O acesso à área, partindo de Recife, é feito através da rodovia federal BR 232 por cerca de $36 \mathrm{~km}$ até chegar-se ao município de Vitória de Santo Antão. A partir daí toma-se a rodovia estadual PE 45 rumo sul em direção ao município de Escada, percorrendo-se cerca de $8 \mathrm{~km}$ até o acesso à Vila de Jussaral. Do entroncamento da PE 45 toma-se estrada vicinal secundária rumo leste e percorre-se cerca de 5 km até chegar-se à localidade do distrito de Jussaral (Figura 5).

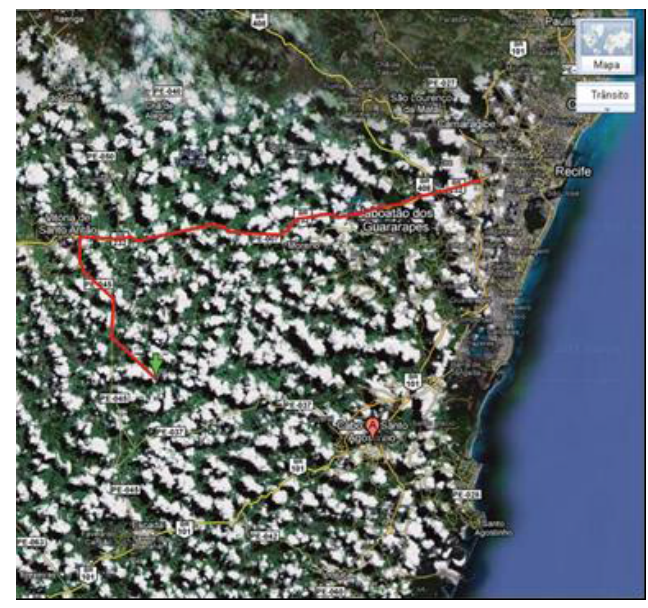

Figura 5: Mapa de localização da área.

Fonte: Google Earth (2013)

Nesta área encontra-se o granito em estudo, conhecido como "Pedra da Pimenta", que aflora sob a forma de grande maciço rochoso, com comprimento superior em certos pontos a 400 $m$ (Figura 6). Aflora sob a forma de grande maciço rochoso que chega a possuir mais de 5.000 .000 $\mathrm{m}^{3}$ de volume. Dispõem-se também no terreno como maciço elevado, constituindo morros que se destacam na topografia (sendo comuns elevações com altura superior a $100 \mathrm{~m}$ ), ao longo dos quais o granitóide está exposto ou acha-se coberto por fina capa de solo residual. Como os maciços são de grandes dimensões e apresentam bons destaques topográficos, a lavra neste setor não deverá apresentar maiores dificuldades. 


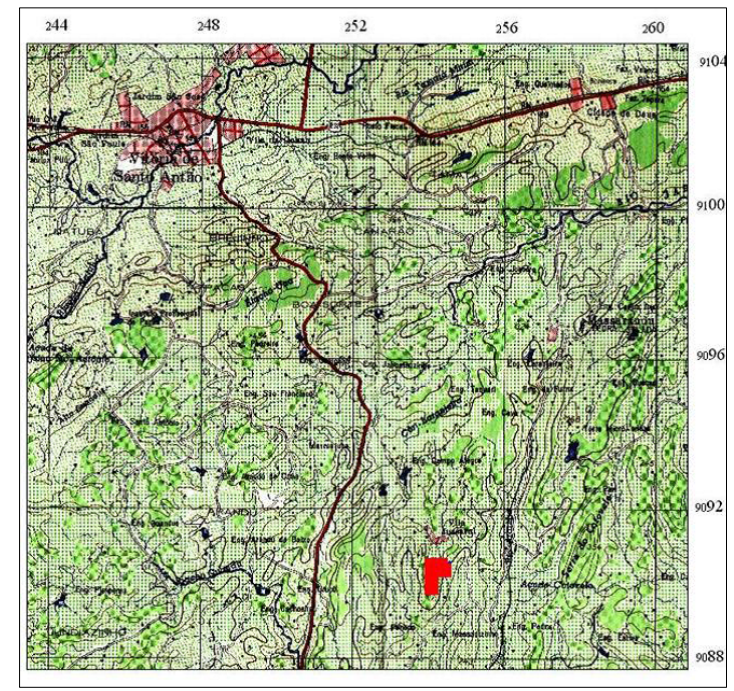

Figura 6: Localização do maciço rochoso destacado em vermelho.

Fonte: FOLHA SC-25-V-AII MI-1371

Com relação à geologia regional, a área está situada na região da Província da Borborema, uma província estrutural da plataforma Sul Americana caracterizada, de há muito, pela riqueza e diversidade do magmatismo granítico, o qual perfaz, em termos gerais, cerca de $30 \%$ de todo o conjunto territorial. Já com relação à geologia local, aflora extenso corpo granitóide pertencente à suíte Itaporanga, aflorante sob a forma de extensos maciços e grandes matacões, os quais se destacam na topografia local. Constitui um tipo de composição calcioalcalina, de alto potássio e composição variando de granítica a granodiorítica, com fácies monsogranitícos e seiníticos, incluindo termos dioríticos. O granito em tela ocorre próximo à Vila Jussaral e se estende pelos engenhos Massaulzinho, Laranjeiras e Morro Pelado.

Salienta-se a homogeneidade do litotipo aflorante, sendo destituído de foliações, fraturamento e deformações cisalhantes, o que facilitará as futuras operações de desmonte do material. No geral trata-se de uma rocha porfiróide, de composição granodiorítica, isotrópica, feldspática, holocristalina, de matriz formada por grãos xenomórficos de feldspato, com presença de quartzo e biotita nos espaços intersticiais.

Em termos macroscópicos o granito possui textura porfirítica, granulação grosseira, sendo constituído por fenocristais de feldspato com até $1,0 \mathrm{~cm}$ de comprimento, orientados em uma matriz escura formada por biotita, anfibólio, quartzo, titanita e uma massa com pequenos grãos de plagioclásio. Apresenta coloração cinza-escura, com manchas róseas a creme.

As observações macroscópicas e a análise petrográfica permitem classificar a rocha como um granodiorito porfirítico perfeitamente aplicável para a produção de brita, e com base na sua composição mineralógica pode-se prever que a possibilidade de sofrer reações de álcali-agregados é bastante reduzida, constituindo-se, portanto em um litotipo perfeitamente utilizável como agregado na indústria da construção civil. Além disso, os resultados de análises petrográficas e dos ensaios de caracterização tecnológica apontam que o ortognaisse em questão apresenta condições técnicas condizentes com o seu emprego como rocha natural na condição de revestimentos de piso e de paredes laterais. 


\section{METODOLOGIA EXPERIMENTAL}

$\mathrm{Na}$ elaboração do estudo de caso foram utilizados softwares comerciais para a determinação dos volumes dos sólidos correspondentes ao corpo mineral e, consequentemente, quantificação das reservas minerais. Foram eles: SKETCHUP PRO 8.0, SURFER 9.0, AUTOCAD 2010, AUTOCAD CIVIL 3D 2014 e o DATAMINE STUDIO 3.0.

Além dos métodos computacionais, utilizou-se para fins de comparação dos resultados obtidos através dos dados de digitalização manual em AUTOCAD dos mapas topográficos disponíveis da região e também dados de campo obtidos com GPS. Neste estudo, os mapas utilizados foram da Fundação de Desenvolvimento da Região Metropolitana do Recife (FIDEM). Para a confecção de um mapa-base, foram necessárias 04 (quatro) dessas projeções ortogonais chamadas de Ortofotocartas disponíveis em escala de 1:10.000.

Para o levantamento planialtimétrico, utilizou-se um aparelho GPS modelo Garmin 76s. O levantamento realizado teve como objetivo comprovar as cotas registradas no mapa-base, fornecer as coordenadas UTM e altitudes do maciço rochoso para em seguida exportá-las por meio de planilhas confeccionadas em Excel 2010 para o software SURFER 9.0.

A metodologia consistiu, basicamente, em construir os DTM's para geração das curvas de nível através dos softwares Sketchup Pro 8.0 e Surfer 9.0. O software AutoCad auxiliou na construção das wireframes, a partir das curvas de níveis, necessárias para a definição do volume dos sólidos representativos do corpo mineral gerados através do software Datamine Studio 3.0.

\section{- $\quad$ SketchUp Pro 8.0}

É uma ferramenta para a apresentação de modelos tridimensionais; uma vez desenhado o modelo, é possível exportá-lo através da versão PRO para outros formatos (2D e 3D), como DWG, DXF, 3DS, OBJ, XSI ou VRML para dar continuidade ao projeto do desenho preliminar. Foram desenvolvidos vários plug-ins destinados a várias funções, onde se pode destacar a importação e exportação de dados para o software SketchUp. O plug-in utilizado para desenvolver o DTM e a partir daí gerar as curvas de níveis foi o Google Earth, que permite a criação de modelos em 3D em Sketchup, possibilitando visualizar a topografia local criada em SketchUp diretamente no seu meio ambiente. Os modelos podem ser gravados num ficheiro no formato KMZ ou KML.

Adotou-se o Sketchup por ser uma ferramenta gratuita e de uso acessível, que possibilitou a elaboração da topografia em 3D e com ela foi possível a obtenção das curvas de nível do terreno localizado na área de Jussaral, objeto desse estudo. O primeiro passo para construção do modelo tridimensional do terreno com suas respectivas curvas de níveis foi importar a imagem correspondente da área no Google Earth; a imagem 2D foi convertida em uma imagem 3D com as curvas do terreno pela ferramenta "ativar o terreno"; desenhou-se um plano com dimensões que cobriram toda a área, e a partir desse plano criaram-se diversos outros planos ao longo do eixo vertical, empilhados um acima do outro com intervalo de 5 em 5 metros; posicionou-se o plano de forma a englobar toda a área desejada e selecionou-se todos os planos para criar as curvas através da ferramenta "Interceptar com o modelo"; apagou-se os planos criados para obtenção das curvas 
de nível, as quais não foram suavizadas e nem georreferenciadas. Para isso, importou-se o desenho para o AUTOCAD a fim de suavizar as curvas e georreferenciá-las.

\section{- $\quad$ SURFER 9.0}

O Surfer ${ }^{\circledR}$ é um pacote de programas gráficos que pode ser utilizado para o cálculo e a confecção de mapas de variáveis a partir de dados regularmente distribuídos. É uma importante ferramenta computacional, que usa algoritmos matemáticos para gerar suas curvas.

A aplicação deste programa foi principalmente para modelar as curvas de nível a partir de dados GPS. Diferentemente do SketchUp, que trabalha diretamente com as imagens do Google Earth, o Surfer necessita das coordenadas tridimensionais do campo georreferenciadas. Um mapa é construído a partir das posições espaciais de pontos colhidos no campo e são representados pelos valores $X, Y$ e $Z$. As coordenadas são os valores $X$, posição do ponto no eixo da ordenada leste-oeste, e $Y$, posição na abscissa norte-sul, e $Z$ é o valor observado da variável nesse ponto. As coordenadas foram colhidas em UTM.

O Surfer 9.0 possui uma planilha de entrada de dados, que permite importar planilhas de diversos aplicativos, como Excel ${ }^{\circledR}$. Aberta a planilha, basta completar as células com os dados, podendo colocar rótulos na primeira linha das colunas com o nome das variáveis. O usual é que a primeira coluna contenha os valores de $X$, a segunda os valores de $Y$ e na terceira os valores da variável Z.

A partir das coordenadas do ponto e dos valores assumidos pela variável nesses pontos coletados através do GPS em campo, confeccionou-se uma planilha no Excel. A parte mais importante na geração desses mapas é a escolha do método de interpolação, pois métodos diferentes geram resultados diferentes, podendo conduzir a conclusões diversas. Utilizou-se para confecção dos mapas planialtimétricos o método da Krigagem Ordinária. Ao definir o método e opções, gerou-se um arquivo da malha de amostragem com os dados dispostos regularmente, com a extensão .GRD.

\section{- $\quad$ AutoCAD 2010}

AutoCAD é um software do tipo CAD - Computer Aided Design (Desenho Auxiliado por Computador) utilizado principalmente para a elaboração de peças de desenho técnico em duas dimensões (2D) e para criação de modelos tridimensionais (3D). No presente trabalho, essa ferramenta computacional foi utilizada para gerar as curvas de níveis a partir das imagens digitalizadas dos mapas bases da FIDEM (Ortofotocartas).

Inicialmente digitalizaram-se os mapas físicos disponibilizados pela FIDEM. Para a confecção de um mapa-base são necessárias 04 (quatro) dessas projeções ortogonais chamadas de Ortofotocartas, numa escala de 1:10.000; os mapas digitalizados geraram uma imagem que foi importada para o AutoCAD 2010, e o processo de construção das curvas de nível foi feito digitando-se polilinhas sobre a imagem até completar toda a região de interesse. Após esse processo, de acordo com as cotas das curvas de nível do mapa, foram incluídos tais valores nas curvas desenhadas no AUTOCAD 2010. 
A princípio, para fornecer um resultado satisfatório dentro do objetivo inicial do trabalho, cobriu-se uma área relativamente grande em torno do maciço rochoso de interesse (Pedra da Pimenta), que tornou-se o mapa-base para comparação dos resultados obtidos nas outras metodologias utilizadas, pois possui uma precisão considerada razoável dentro da etapa preliminar de avaliação de maciços.

Dessa forma, comparou-se os volumes calculados com as outras metodologias com esse mapa-base definindo-se as variações em relação aos volumes determinados a partir dos diferentes DTM's, considerando-se melhor o resultado que mais se aproxima do volume calculado por esse mapa-base.

Para facilitar as próximas etapas de processamento computacional e comparação de resultados, restringiu-se a modelagem às curvas de nível referentes ao maciço rochoso e a uma região com cerca de 25 ha localizada junto ao denominado morro da Pimenta. Logo após a escolha da área para a modelagem, cada curva de nível restante foi cotada, recebendo o valor da altitude correspondente.

\section{- $\quad$ AutoCAD Civil 3D 2014}

O AutoCAD Civil 3D possui todas as funcionalidades do software CAD, gera arquivos no formato DWG e também conta com as funcionalidades de geoprocessamento do AutoCAD Map 3D. No presente trabalho utilizou-se esta ferramenta computacional para ajuste, suavização e georreferenciamento das curvas de nível importadas do software SketchUp Pro 8, para em seguida utilizá-las para confecção das wireframes no software DATAMINE STUDIO 3.0.

A primeira etapa da utilização do AutoCad Civil 3D é a exportação das curvas geradas no software SketchUp Pro 8 no formato ".dwg" através do comando "Open"; as curvas de nível estão "partidas" em diversos "pedaços", e para uni-las utiliza-se a ferramenta "Join" para então suavizálas como "Polylines".

Depois de selecionar as múltiplas polylines utiliza-se a opção Spline digitando " $\mathrm{S}$ " no prompt de comando. Feito isso, as curvas de níveis estão prontas para serem exportadas para o software DATAMINE STUDIO 3.0 para fins de construção das devidas wireframes.

\section{- $\quad$ DATAMINE STUDIO 3.0}

O DATAMINE proporciona um conjunto de comandos para entrada e manipulação de dados associados a um amplo nível de capacidades estatísticas, gráficas e de processamento, especialmente projetados para dados geológicos e de mineração, desde o manuseio de dados iniciais até a programação de produção, planejamento e acompanhamento da lavra.

Primeiramente exportou-se os arquivos das curvas de níveis geradas a partir do Surfer 9.0 e do SketchUp Pro 8 no formato "dwg." para a modelagem das superfícies através de Modelos Digitais de Terreno (DTM). As superfícies foram modeladas como DTMs por uma malha de triângulos, criada a partir de pontos tridimensionais coletados através da superfície das curvas de níveis exportadas. 
Em seguida iniciou-se o processo de modelagem geométrica da jazida partindo da malha triangulada gerada. O termo técnico para definir este tipo de modelo é wireframe, que permite o cálculo preciso do volume definido pelo contorno, pois representa a forma geométrica dos corpos e também permite a criação de modelo de blocos. Uma vez modeladas as estruturas, o DATAMINE converteu as wireframes em um modelo de bloco.

O sistema DATAMINE utiliza este tipo de modelo em conjunto com avançados sistemas de controle de subdivisão e otimização das dimensões dos blocos e sub-blocos, gerando uma modelagem detalhada da jazida. Resumidamente, o software "preenche" o modelo wireframe com blocos e sub-blocos, de modo a garantir que o modelo de blocos final seja representativo em relação à wireframe e permita a modelagem das variáveis dentro do modelo. Após gradear o modelo de blocos pôde-se então estimar o volume do maciço rochoso através da quantidade de blocos de volume conhecido que estão incluídos no espaço correspondente à jazida mineral ou que estão posicionados dentro da cava projetada.

A cava experimental foi gerada a partir da utilização de ferramentas de Pit Design do Datamine Studio 3.0. Para fins de comparação dos volumes calculados através dos diferentes modelos criados delimitamos uma área hipotética a qual foi denominada área base, que foi desenhada aleatoriamente de forma a englobar um local onde exista informação da topografia das 3 metodologias utilizadas para geração do modelo digital do terreno (DTM). Após definição da área base o volume de maciço rochoso foi determinado a partir de um DATUM estabelecido na cota altimétrica de $250 \mathrm{~m}$.

Assim, após a construção dos modelos em cada software, fez-se as comparações dos volumes calculados com o mapa-base proveniente da digitalização das ortofotocartas definindo-se as variações em relação aos volumes determinados a partir dos diferentes Modelos Digitais de Terreno (Digital Terrain Model - DTM's), considerando-se melhor o resultado que mais se aproxima do volume calculado por esse mapa-base.

\section{DISCUSSÃO DE RESULTADOS}

Através da combinação dos softwares mencionados acima, foi possível gerar os DTM's e realizar os cálculos de volume do maciço rochoso. Os resultados foram gerados dentro da área base, com o intuito de se comparar as diferentes metodologias para o cálculo do volume gerado a partir da respectiva modelagem de blocos no Datamine.

- 10 Modelo - SketchUp Pro 8.0

Os contornos gerados pelo uso do software SketchUp Pro 8.0 têm relativamente boa confiabilidade. As curvas foram espaçadas de 5 em 5 metros (Figura 7). 


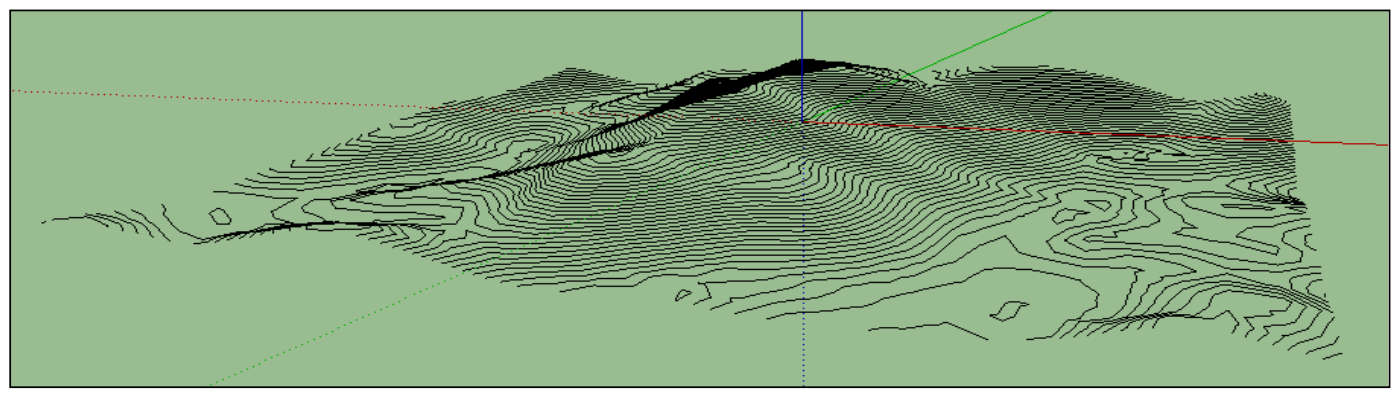

Figura 7: Superfície topográfica gerada a partir do SketchUp Pro 8.

A partir deste modelo topográfico 3D importou-se as curvas para o AutoCAD Civil 3D e em seguida para o DATAMINE onde foi desenvolvido o Modelo Digital do Terreno (DTM) correspondente à topografia da área de estudo (Figura 8).

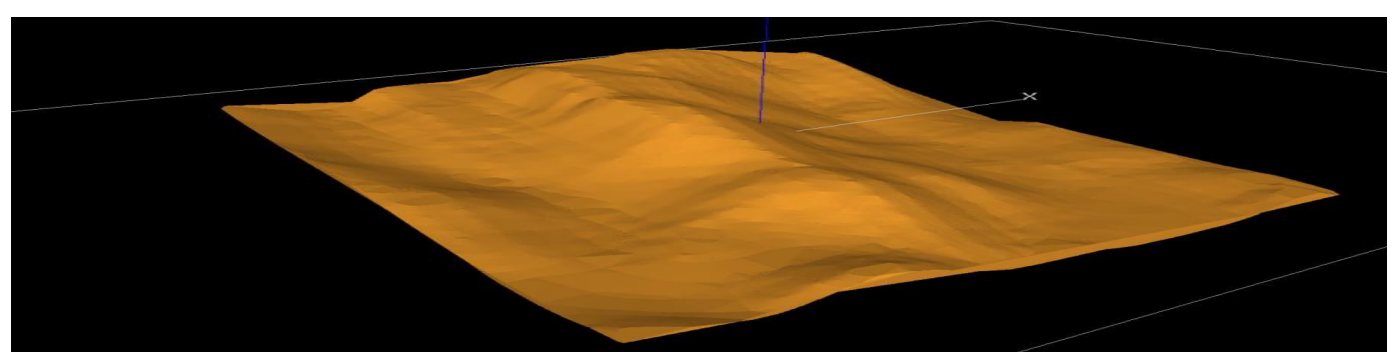

Figura 8: DTM correspondente à topografia do terreno da área gerada a partir do DATAMINE.

A partir do correspondente DTM da topografia da área de interesse foi gerado um modelo de blocos e em seguida, calculado o volume do maciço rochoso (Figura 9).

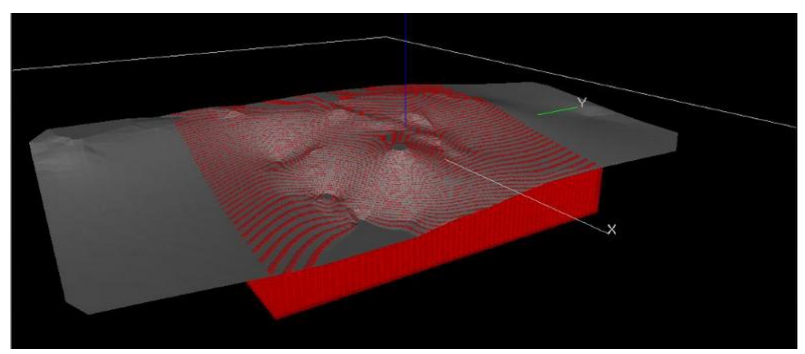

Figura 9: Modelo de blocos do maciço rochoso.

Com isso, foi possível calcular o volume do sólido e, em seguida, criar o pit final para o desenvolvimento da mineração. O volume encontrado utilizando o modelo SketchUp com o DATAMINE foi de $11.198 .946,6 \mathrm{~m}^{3}$ (metros cúbicos).

\section{- $\quad 20$ Modelo - SURFER 9.0}

Com os dados coletados em campo com equipamento GPS foi possível preparar o contorno usando o SURFER 9.0 (Figura 10). Por este método não foi necessário suavizar as curvas de nível no AutoCAD, uma vez que este já é feito pelo próprio SURFER. Em seguida, trabalhou-se no AutoCAD a colocação do relevo, e depois exportou-se para o DATAMINE para a geração do DTM e do modelo de blocos para calcular o volume do depósito. 


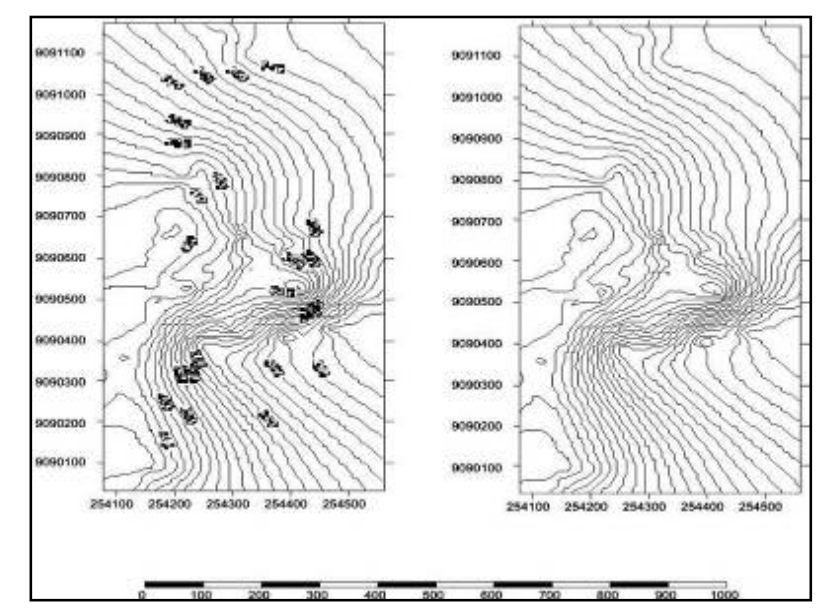

Figura 10: Curvas de nível geradas a partir do SURFER 9.0.

O volume total de massa de rocha obtido no DATAMINE que pode ser extraído da cava gerada com os dados do SURFER é $13.812 .177,1 \mathrm{~m}^{3}$ (metros cúbicos).

\section{- 3o Modelo - Ortofotocartas}

As curvas de nível correspondentes à topografia do maciço rochoso obtidos pela digitalização no software AutoCAD dos mapas de contorno da Fundação de Desenvolvimento da Região Metropolitana do Recife - FIDEM são mostrados na Figura 11.

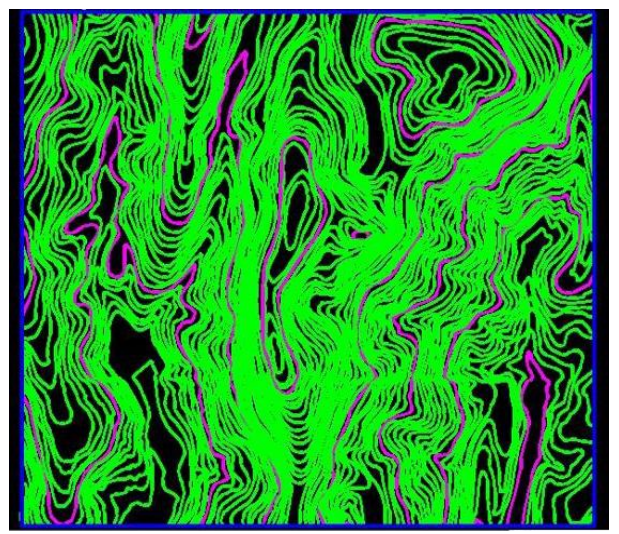

Figura 11: Curvas de nível geradas a partir da digitalização das ortofotocartas.

Assim, a partir das curvas de nível, foi possível gerar o DTM, e o modelo de blocos no DATAMINE (Figura 12).

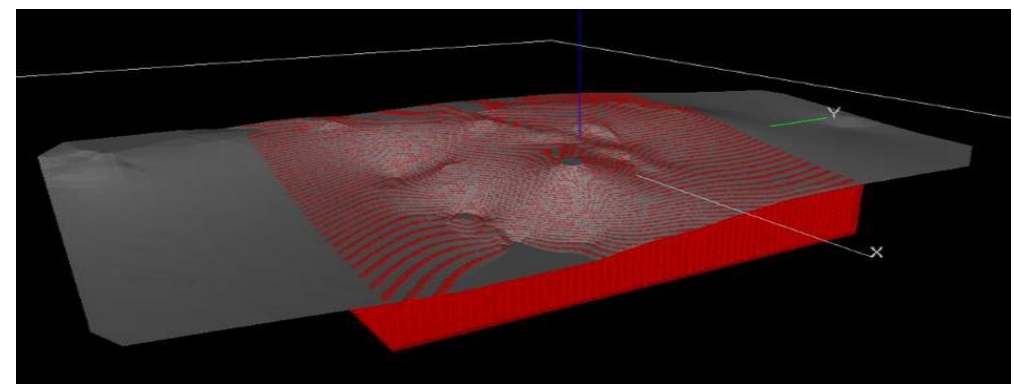

Figura 12: Modelo de blocos dos dados obtidos com a digitalização das ortofotocartas.

Assim, através deste modelo gerado por estes mapas de contorno da FIDEM, o volume de massa de rocha da jazida em estudo é de $12.757 .141,6 \mathrm{~m}^{3}$ (metros cúbicos). 


\section{- Comparação do cálculo da reserva do maciço rochoso}

A Tabela 1 mostra os resultados de volumes obtidos com as três metodologias de modelagem dos maciços rochosos e a diferença em termos absolutos e percentuais entre os volumes calculados pelas 2 metodologias em relação ao volume calculado através das ortofotocartas da FIDEM, que é considerado o mais preciso entre os modelos estudados.

Tabela 1: Resultados dos volumes das três metodologias e a diferença entre as mesmas.

\begin{tabular}{c|c|c|c}
\hline Método & $\begin{array}{c}\text { Volume } \\
\left(\mathbf{m}^{\mathbf{3}}\right)\end{array}$ & $\begin{array}{c}\text { Diferença de volume } \\
\left(\mathbf{m}^{\mathbf{3}} \mathbf{)}\right.\end{array}$ & $\begin{array}{c}\text { Diferença } \\
\mathbf{( \% )}\end{array}$ \\
\hline SketchUp Pro 8 & $11.198 .946,60$ & $1.558 .195,00$ & 12,21 \\
SURFER 9.0 & $13.812 .177,10$ & $1.055 .035,50$ & 8,27 \\
Ortofotocartas & $12.757 .141,60$ & - & - \\
\hline
\end{tabular}

Observa-se que as diferenças dos volumes de reservas obtidos com os softwares SketchUp e Surfer em relação ao volume das Ortofotocartas podem ser consideradas aceitáveis, visto que para estimativas iniciais de ordem de grandeza pode ser admitido um erro de até $40 \%$, e para estimativas fatoradas, como é esse caso, são admitidas variações com precisão de até $\pm 15 \%$ nas estimativas, levando em consideração as incertezas existentes em relação aos dados coletados. Este fato permite afirmar que as metodologias de combinação de softwares de baixo custo empregadas são satisfatórias para a avaliação preliminar de volumes de maciços rochosos dentro da precisão desejada para a fase de investigação inicial de maciços rochosos, mas não na fase final de avaliação onde deve-se ter uma estimativa mais fidedigna com variações máximas de $5 \%$ (Souza, 1991).

\section{CONCLUSÕES}

Pelos resultados obtidos nas três metodologias desenvolvidas no presente trabalho conclui-se que é possível realizar-se a modelagem geométrica de maciços rochosos utilizando-se ferramentas computacionais de baixo custo tais como os softwares SketchUp Pro 8.0, Surfer 9.0 e AutoCad com dados obtidos no Google Earth. Os dados obtidos junto a plataforma Google Earth através do software SketchUp Pro 8.0 mostraram-se compatíveis com os resultados obtidos de fontes confiáveis como as ortofotocartas e levantamento de campo com GPS.

As diferenças entre os resultados da modelagem e cálculo de volume nas diversas metodologias foram inferiores a 15\%, indicando uma boa aderência entre as diferentes formas de obtenção de dados das superfícies planialtimétricas através das metodologias aplicadas para elaboração de Modelos Digitais de Terrenos - DTM's.

A ferramenta DATAMINE STUDIO mostrou-se extremamente favorável para modelagem geométrica de maciços rochosos através da geração de modelos de blocos e cálculo dos respectivos volumes.

Portanto, conclui-se que, através do uso de ferramentas computacionais pode-se desenvolver metodologias de baixo custo e fácil implantação agilizando o processo de avaliação preliminar de maciços rochosos com precisão compatível para uma etapa inicial de prospecção mineral conforme foi demonstrado ao longo do desenvolvimento do trabalho. 


\section{REFERÊNCIAS}

Barnes, M. P. (1980). Computer-Assisted Mineral Appraisal and Feasibility. New York: Soe. Min. Eng.

Carmo, I. M. (2013). Estudo Comparativo de Ferramentas Computacionais para Modelagem geométrica e Cubagem de Maciços Rochosos. Dissertação de Mestrado, Universidade Federal de Pernambuco, Recife, PE, Brasil.

Carmo, F. A. R., Curi, A., \& Sousa W. T. (2006). Otimização econômica de explotações a céu aberto. Revista Escola de Minas, 59(3), 317-321.

CPRM - Serviço Geológico do Brasil (2001). CD-ROM.

Curi, A., Neme, M. B., Silva, J. M., \& Carneiro, A. C. B. (2011) Realização de projeto de lavra de mina subterrânea com utilização de aplicativos específicos. Revista Escola de Minas, 64, 519524.

Curi, A., Pereira, M. A., Sousa, W. T., \& Silva, V. C. (2013). Final open pit design for Monte Raso phosphate mine. International Journal of Modern Engineering Research, 3, 3780-3785.

Curi, A. (2014). Minas a Céu Aberto - planejamento de lavra. São Paulo: Oficina de textos.

Devore, J. L. (2006). Probabilidade e estatística: para engenharia e ciências. São Paulo: Pioneira Thompson Learning.

Gama, C. A. J. V. D. (1974) - Modelo computacional de uma exploração mineira. Revista Geologia e Metalurgia, 35, $289-324$.

Gama, C. A. J. V. D. (1986). Evolução dos Métodos de Cálculo de Reservas Minerais. Revista Brasil Mineral, (28), 36-42.

Girodo, A. C. (2006). Planejamento da produção mineral: material didático instrucional. Belo Horizonte: IETEC.

Google Earth. Acesso a Jussaral por Recife. 2013.

Hustrulid, W., Kuchta, M., \& Martin, R. (2013). Open Pit Mine - planning \& design. $3^{\text {rd }}$ edition. New Youk: CRC Press

Pinto, C. L. L., \& Dutra, J. I. G. (2008). Introdução ao planejamento e operação de lavra (a céu aberto e subterrânea). Belo Horizonte: UFMG.

Revuelta, M. B. \& Jimeno, C. L. (2012). Manual de Evaluación y Diseño de Explotaciones Mineras. Madrid: Entorno Gráfico.

Sad, J. H. G., \& Valente, J. M. (2007). Delineação de depósitos minerais. Belo Horizonte: Rona.

Sousa, J. C. (1991). Estudo de viabilidade econômica preliminar de alternativas para o beneficiamento do carvão de Candiota. Dissertação de Mestrado, Universidade Federal do Rio Grande do Sul, Porto Alegre, RS, Brasil.

Tomi, G. Modelagem geológica informatizada em Datamine. In J. K. Yamamoto. Avaliação e Classificação de Reservas Minerais (pp. 164-191). São Paulo: Editora da Universidade de São Paulo.

Yamamoto, J. K. (2001). Avaliação e Classificação de Reservas Minerais. São Paulo: Editora da Universidade de São Paulo.

Yamamoto, J. K., \& Conde, R. P. (1996). Avaliação de reservas por métodos computacionais: um estudo de caso na Mina de Canoas 2 (PR). Revista Brasileira de Geociências, 26(1), 35-42.

Yamamoto, J. K., \& Landim, P. M. B. (2013). Geoestatística: conceitos e aplicações. São Paulo: Oficina de textos. 